\title{
Congenital rubella and diabetes mellitus
}

\author{
M. A. Burgess • J. M. Forrest
}

Received: 4 September 2008 / Accepted: 14 October 2008 / Published online: 26 November 2008

(C) Springer-Verlag 2008

Keywords Congenital rubella $\cdot$ Diabetes mellitus $\cdot$ Rubella . Rubella virus

\section{Abbreviations \\ CR congenital rubella \\ IAA insulin autoantibody}

\section{To the Editor:}

In his interesting Editorial on the association between congenital rubella (CR) and diabetes mellitus, Edwin Gale proposes that $\mathrm{CR}$ is the only viral infection that can claim, somewhat tenuously, to be a cause of type 1 diabetes [1]. But imbedded in his discussion is the suggestion that this association may have occurred by chance as there are relatively few well-documented reports of individuals with insulin-dependent, childhood-onset, antibody-positive disease in the literature. However, Gale appears to accept an association with type 2 disease.

We believe, on the basis of clinical reports and on its pathogenesis, that $\mathrm{CR}$ leads to both type 1-like and type 2like diabetes; that the prevalence of diabetes in children and adolescents with CR is higher than the 1\% suggested in the Editorial; and that about $20 \%$ of CR patients develop type 2-like disease as they age.

M. A. Burgess has published work under her maiden name, Menser.

M. A. Burgess $(\bowtie) \cdot$ J. M. Forrest

National Centre for Immunisation Research,

University of Sydney and the Children's Hospital at Westmead,

Locked Bag 4001,

Westmead, NSW 2145, Australia

e-mail: Margarb1@chw.edu.au
Congenitally acquired rubella viral infection causes inhibition of intrauterine cellular growth [2]. Live-born infants remain actively infected [3] and are mostly of low birthweight $[4,5]$. Some infants also have microvascular disease [6], and most have an altered cellular and humoral immune response to rubella virus [7]. Rubella virus has been isolated from the pancreas of infants at autopsy [3] and intimal proliferation has been documented in pancreatic blood vessels [8]. Between 3 and 12 months of age some infants develop a generalised rash and severe pneumonitis [9]. This condition, which can be fatal, is thought to be due to an immunological process, but may respond to steroids.

The first cohort of CR patients to be carefully studied for diabetes was born in 1940-1942 and examined by us as adults [10]. This cohort was drawn partly from the patients first described by the Australian ophthalmologist Dr (later Sir) Norman Gregg [4]. Survival of infants born with CR at that time was far poorer than that of those born following the large worldwide outbreak of rubella in 1964-1965 because more effective neonatal intensive care and surgery increased the survival prospects of affected infants. So long-term survivors of the 1941 and earlier outbreaks have less extensive pathology than many who have survived since then. Our adult cohort has been followed up progressively to the age of 60 years [11]. By then, seven of $32(22 \%)$ had type 2-like diabetes: two of the three requiring insulin had diabetic retinopathy and elevated levels of GAD antibodies and insulin autoantibodies (IAAs); one of the seven had elevated levels of GAD and IAAs. Seven individuals had clinical or biochemical evidence of thyroid disease, and eight of the 11 women in the cohort had experienced early menopause, three before the age of 38 years. We had previously recorded that some of this cohort were found to have pancreatic islet cell antibodies before they had reached the age of 30 years [12]. 
Even so, it appears that these individuals have predominantly type 2-like disease.

However, in the early literature there are a number of CR patients with childhood- or adolescent-onset type 1-like disease, some with severe diabetic complications, who did not come to Gale's notice $[10,12]$. So we consider that the children and adolescents described by L. Cooper and colleagues following the 1964-1965 outbreak in New York, $6 \%$ of whom had type 1-like diabetes, are more likely than not to be representative of the rate of type 1 disease in CR in most Western communities [13].

It seems to us that this association of CR with type 1 diabetes was not a chance one, and that $\mathrm{CR}$ promoted both autoimmune type 1 diabetes and type 2 disease, in view of the CR syndrome's association with autoimmune thyroiditis [14], the 'late-onset' pulmonary and skin disease described in infants by W. Marshall and colleagues [9], the lymphocytic infiltration seen in infant pancreas at autopsy [15] and, in some individuals, the detection of pancreatic islet cell antibodies (even if the detection of these antibodies is no longer considered a reliable test) and IAAs [11, 12, 13]. Perhaps this immunopathology was superimposed on the likely low intrauterine complement of potentially functioning islet and, in some instances, other endocrine cells.

Congenital rubella is a multi-system disease with widespread vascular and organ involvement. Of interest is the fact that at present the International Society for Pediatric and Adolescent Diabetes (ISPAD) Clinical Practice Consensus Guidelines 2006-2007 list congenital rubella diabetes, not under type 1 or type 2 disease but in the third category of 'other specific types' of diabetes.

We do not suggest that CR was ever responsible for a discernible proportion of the global cases of diabetes. We, like others, rejoice that vaccination has resulted in the near elimination of CR from many countries. Although this is not yet so in low-income areas, rubella vaccination will gradually become a universal strategy. We remain optimistic that, in the interim, the science surrounding the aetiology of diabetes in CR will be elucidated and perhaps provide clues to broader answers about the pathogenesis of idiopathic 'type 1' and 'type 2' diabetes. We hope that this discussion, prompted by Gale, will stimulate the process.
Acknowledgements We thank M. Honeyman (Walter and Eliza Hall Institute of Medical Research, Melbourne, VIC, Australia) for drawing our attention to the Editorial, and K. Donaghue (Institute for Endocrinology, Children's Hospital at Westmead, Westmead, NSW, Australia) for the ISPAD guidelines.

Duality of interest The authors declare that there is no duality of interest associated with this manuscript.

\section{References}

1. Gale EAM (2008) Congenital rubella: citation virus or viral cause of type 1 diabetes? Diabetologia 51:1559-1566

2. Plotkin SA, Boué A, Boué JG (1965) The in vitro growth of rubella virus in human embryo cells. Am J Epidemiol 81:71-85

3. Cooper LZ, Green RH, Krugman S et al (1965) Neonatal thrombocytopenic purpura and other manifestations of rubella contracted in utero. Am J Dis Child 110:416-427

4. Gregg NM (1941) Congenital cataract following German measles in the mother. Trans Ophthalmol Soc Aust 3:35-46

5. Naeye RL, Blanc W (1965) Pathogenesis of congenital rubella. JAMA 194:1277-1283

6. Menser MA, Reye RDK (1974) The pathology of congenital rubella. Pathology 6:215-222

7. Cooper LZ (1985) The history and medical consequences of rubella. Rev Infect Dis 7(Suppl 1):S2-S10

8. Rorke LB, Spiro AJ (1967) Cerebral lesions in congenital rubella syndrome. J Pediatr 70:243-255

9. Marshall WC (1973) The clinical impact of intrauterine rubella. In: Elliott $\mathrm{K}$, Knight $\mathrm{J}$ (eds) Intrauterine infections (Ciba Foundation Symposium 10, new series). Associated Scientific Publishers, Amsterdam, pp 3-22

10. Menser MA, Forrest JM, Bransby RD (1978) Rubella infection and diabetes mellitus. Lancet 1:57-60

11. Forrest JM, Turnbull FM, Sholler GF et al (2002) Gregg's congenital rubella patients 60 years later. Med J Aust 177:664667

12. Menser MA, Forrest JM, Bransby RD, Hudson JR (1982) Long term observations of diabetes and the congenital rubella syndrome in Australia. In: Mimura G, Baba S, Goto Y, Köbberling J (eds) Clinicopathogenetic genesis of diabetes mellitus. Excerpta Medica, Amsterdam, pp 221-225

13. Ginsberg-Fellner F, Witt ME, Fedun B et al (1985) Diabetes mellitus and autoimmunity in patients with the congenital rubella syndrome. Rev Infect Dis 7(Suppl 1):S170-S176

14. Clarke WL, Shaver KA, Bright GM et al (1984) Autoimmunity in congenital rubella syndrome. J Pediatr 104:370-373

15. Bunnell CE, Monif GRG (1972) Interstitial pancreatitis in the congenital rubella syndrome. J Pediatr 80:465-466 